\title{
Challenges when developing omega-3 enriched foods
}

\author{
Charlotte JACOBSEN \\ Division of Seafood Research, \\ National Institute of Food Research, \\ Technical University of Denmark, \\ Building 221, Søltofts Plads, \\ DK-2800 Kgs. Lyngby, \\ Denmark \\ <cja@aqua.dtu.dk>
}

\begin{abstract}
Due to the polyunsaturated nature of omega-3 fatty acids, lipid oxidation is a major challenge when developing omega-3 enriched foods. In multiphase food systems, several factors can affect lipid oxidation and efficacy of antioxidants, added to prevent lipid oxidation. This review discusses the influence of important factors such as oil quality, delivery systems for omega-3 fatty acids, processing conditions, composition of the food matrix on lipid oxidation in different omega-3 enriched foods (milk, yoghurt, mayonnaise and mayonnaise-based salads, dressing, energy bar and fish paté). Moreover, the effect of different antioxidants (tocopherol, EDTA, lactoferrin, caffeic acid, ascorbic acid, ascorbyl palmitate, propyl gallate, gallic acid, as well as lipophilized antioxidants) is compared in different food systems.
\end{abstract}

Key words: omega-3 fatty acids, lipid oxidation, dairy products, mayonnaise, dressing, bread, antioxidants
In the 1970s, Bang \& Dyerberg discovered that Greenland Inuits, who consumed large amounts of marine lipids rich in long chain omega-3 polyunsaturated fatty acids (omega-3 PUFA) as part of their native lifestyle, had a much lower cardiovascular mortality (10-30\%) compared with the Danes, who consumed much lower levels of these lipids (Dyerberg and Ho, 1979). The two most important marine omega-3 PUFA are eicosapentaenoic acid (EPA, 20:5 n-3) and docosahexaenoic acid (DHA, 22:6n-3). Since the discoveries by Bang and Dyerberg, interest in the health benefits of marine omega-3 PUFAs has grown into a large research area. The beneficial health effects of omega-3 PUFA have recently been reviewed by Ruxton et al. (2007). Some of the proposed beneficial health effects include reduction of cardiovascular disease risk, antiinflammatory effects, including reduction of symptoms of rheumatoid arthritis and Crohn's disease and reduction of the risk of certain cancer forms. DHA is particularly important in the development of brain and nervous tissue in the infant. A high intake of EPA and DHA has also been associated with lower risk of developing Alzheimers and depressions.

Due to the increasing evidence about the health beneficial effects of EPA and DHA, and due to the fact that populations in several parts of the world have a too low intake of seafood and thereby also a too low intake of EPA and $\mathrm{DHA}$, there is a growing interest in the industry for applying fish oils in foods. Currently, functional foods containing omega- 3 lipids are one of the fastest growing food product categories in the United States and Europe, and there are already many omega-3 PUFA enriched products on the market.
Due to their polyunsaturated nature, omega-3 PUFA are highly susceptible to lipid oxidation, which will lead to the formation of undesirable fishy and rancid off-flavours. Such off-flavours can lead to consumer rejection of omega-3 enriched foods. It is thus crucial that lipid oxidation is prevented if such products are to become successful in the marketplace. As will be discussed later, many factors can affect lipid oxidation in complex food matrices, and different means are required to reduce or prevent lipid oxidation in different products. In our lab, we have investigated some of the most important factors affecting oxidation, as well as means to prevent oxidation in the following fish oil enriched food products: mayonnaise, dressing, mayonnaise-based salads, milk, milk drink, yoghurt, yoghurt drink, energy bar, bread, buns and fish paté. This presentation will summarize some of our most important findings from this work. As an introduction to the subject, the basic chemistry of lipid oxidation is summarized.

\section{Lipid oxidation and measurement of lipid oxidation}

The basic lipid oxidation reactions are summarized in figure 1. Initially, the polyunsaturated lipid will, in the presence of coloured sensitizers and light, metal ions, already existing free radicals or heat, form free lipid radicals. These free lipid radicals will react with oxygen, whereby lipid peroxyl radicals are formed. Subsequently, the peroxyl radicals will react with a new lipid molecule, whereby the lipid hydroperoxides (peroxides) are formed. The peroxides are also termed primary oxidation products and they are tasteless. However, peroxides may, in the presence of heat or metal ions, be decomposed into secondary volatile oxidation products (volatiles), including alcohols, aldehydes, ketones and hydrocarbons, which are responsible for the off-flavours formed due to oxidation. Decomposition of peroxides by metal ions will also lead to the formation of free radicals that can further catalyze oxidation. Some of the volatile oxidation products formed from omega-3 PUFA include propanal, 2-pentenal, 3-hexenal, 4-heptenal, 2,4-heptadienal, 2,6-nonadienal, 2,4,7-decatrienal,1-penten-3-one and 1,5octadien-3-one. The off-flavours formed from omega-3 PUFA oxidation are particularly unpleasant and are often described as fishy, painty and rancid. Furthermore, the human sensory apparatus has a low threshold for volatile off-flavours resulting from oxidation of omega-3 PUFA, meaning that the off-flavours can be detected by the consumer at lower levels than off-flavours formed due to oxidation of omega-6 PUFA, which are found in high levels in many plant oils (Frankel et al., 2005). As indicated in figure 1, free radicals can be measured by electron spin resonanse. Peroxides are often measured by spectrophotometry, whereby a peroxide value can be obtained. Lipid hydroperoxides contain conjugated dienes, which can also be measured by spectrophotometry. Aldehydes can be measured by the anisidine or TBARS method, which are unspecific methods that determine compounds reacting with $p$-anisidine and thiobarbituric acid, respectively. The methods will mainly determine 2-alkenals and malonaldehyde, respectively. GC-MS is a more specific and sensitive method 


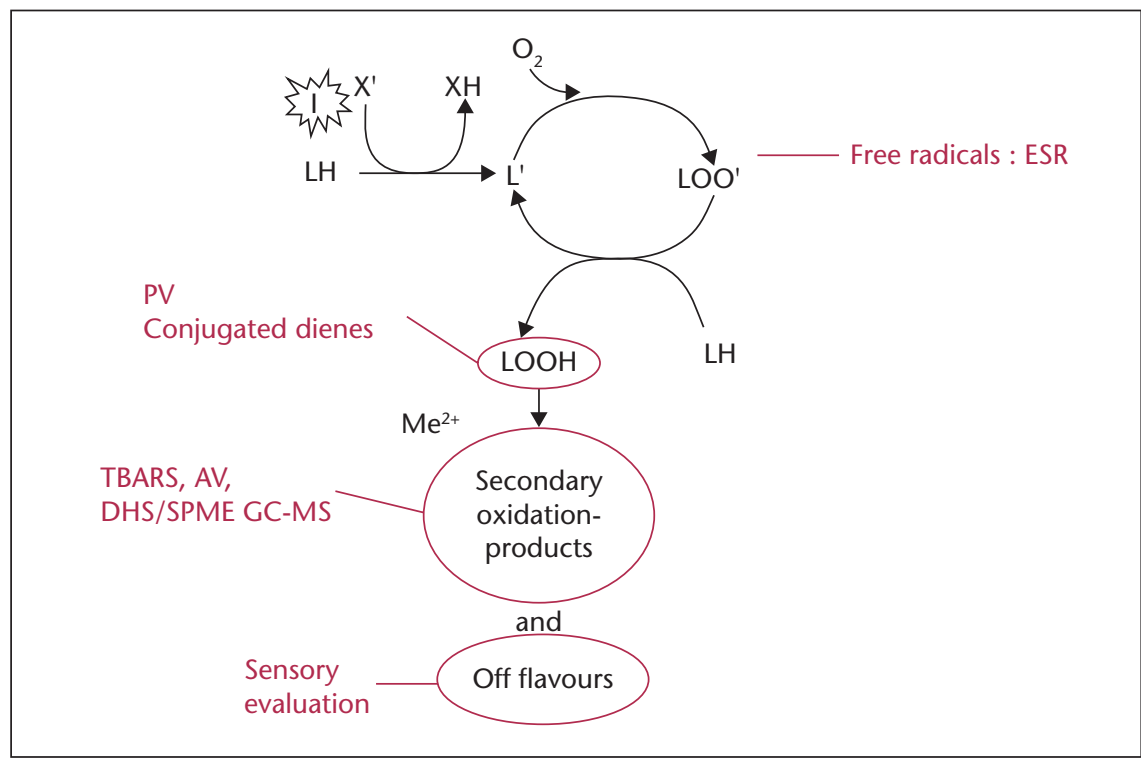

Figure 1. Lipid oxidation reactions and examples of methods used for detection of oxidation products.

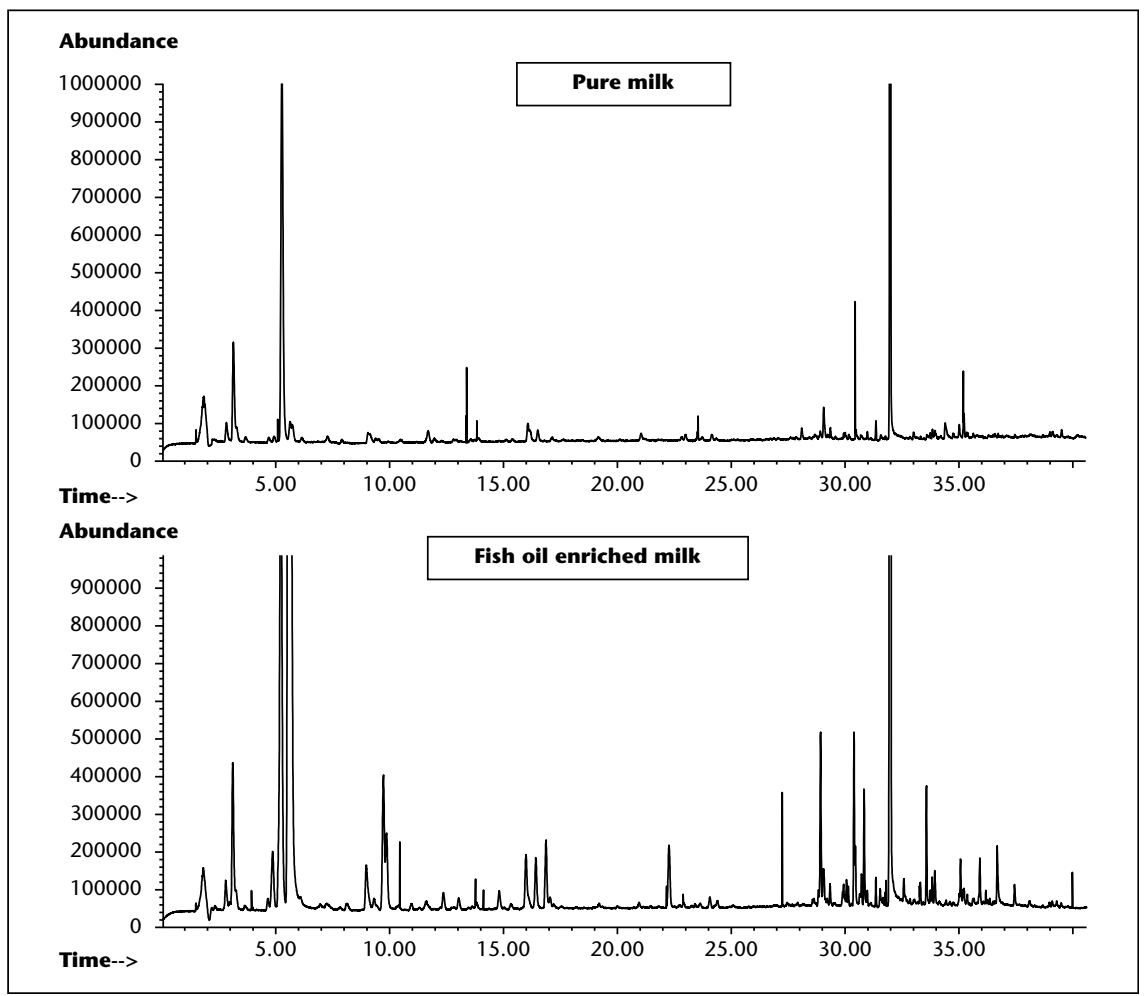

Figure 2. Total ion chromatograms of volatiles collected from pure milk and fish oil enriched milk, both stored at $2{ }^{\circ} \mathrm{C}$ for 14 days. Reprinted from Venkateshwarlu G, Let MB, Meyer AS, Jacobsen C (2004). Chemical and olfactometric characterization of volatile flavour compounds in a fish oil enriched milk emulsion. J Agric Food Chem 52: 311-7 with permission from ACS Publications.

to determine secondary oxidation products. This method will not only determine aldehydes, but also alcohols, ketones and hydrocarbons. Different methods such as static and dynamic headspace and solid phase microextraction
(SPME) are available for collecting the volatiles from the food matrix before injection into the GC. In our lab, we use dynamic headspace or SPME together with GC-MS for determination of volatile oxidation products.

\section{Identification of important volatiles from omega-3 enriched foods: milk as an example}

We have used dynamic headspace GC-MS to determine the volatiles profiles in conventional milk and fish oil enriched milk after storage at $2{ }^{\circ} \mathrm{C}$ for 14 days. As illustrated in figure 2 , a total of 16 volatiles were identified in the pure milk, whereas 62 volatiles were identified in fish oil enriched milk (Venkateshwarlu et al., 2004a). Most of the compounds isolated from pure milk were ketones, especially methyl ketones, straight chain aldehydes and n-alcohols. The methyl ketones are characteristic for pasteurized milk. The volatiles identified in fish oil enriched milk were mostly carbonyl compounds encompassing alkenals, alkadienals, alkatrienals and vinyl ketones. Subsequently, we used GC-olfactometry to identify the odour of the volatiles detected in fish oil enriched milk. On the basis of the results, we concluded that despite their potency, none of the separated individual volatiles gave rise to the same fishy or metallic odours that were observed in oxidized fish oil enriched milk, and we suggested that the fishy and metallic odour was due to a combination of several volatiles (Venkateshwarlu et al., 2004a). The GC-olfactometry analysis suggested that 1-penten-3-one, 4-c-heptenal, 1-octen-3-one, 1,5-octadien-3-one, 2,4t,t-heptadienal and 2,6-t,c-nonadienal were the most potent volatiles. Based on these findings, as well as other data from the literature, we selected 1-penten-3-one, 4-c-heptenal, 2,4-t,t-heptadienal and 2,6-t,c-nonadienal for further study, which aimed at investigating whether these four compounds were responsible for the fishy and metallic off-odour and off-flavours. Thus, a sensory panel evaluated the sensory properties of conventional milk to which different combinations and concentrations of these four volatiles had been added (Venkateshwarlu et al., 2004b). By using partial least square regression, it was possible to build a mathematical model that could describe the relationship between the concentration of the four volatiles and the intensity of fishy and metallic off-odour and off-flavours. Interestingly, the models revealed significant main effects of 2,6-t,c-nonadienal and 1-penten-3-one, which suggest that these two compounds could be useful markers for fishy and metallic off-flavours in fish oil and fish oil enriched foods. The response surface plots revealed a curvature effect of 2,6-t,c-nonadienal, compensatory effect of 4-c-heptenal and 2,4-t,t-heptadienal and synergistic effect of 2,6-t,c-nonadienal and 4-c-heptenal in the development of fishy off-flavours (Venkateshwarlu et al., 2004b). 


\section{Factors affecting lipid oxidation in complex food emulsions}

Figure 3 gives an overview of some of the factors that can influence lipid oxidation in food emulsions. Later, examples on how these factors affect lipid oxidation in different fish oil enriched ingredients solubilised in the aqueous or the oil phase may have an effect on oxidation, being it positive or negative. Furthermore, the choice of emulsifier may also significantly affect the rate of lipid oxidation partly due to the ability of the emulsifier to interact with other ingredients in the emulsion. Moreover, in emulsions stabilised by proteins, $\mathrm{pH}$ will generally be either below or above the pl of the protein in order to avoid coalescence of droplets. This results in an either positive or negative surface charge of the droplets. Similarly, charged droplets may also be obtained in emulsions with certain surfactants, such as charged phospholipids. The surface charge of emulsion droplets is important for lipid oxidation catalysed by the presence of trace metal ions, such as $\mathrm{Fe}^{2+}$. Negatively charged emulsion droplets will attract trace metals, which are potentially prooxidative, and bring them into closer proximity of the omega-3 PUFA oil, and this may promote lipid oxidation. If instead an emulsifier, which creates a positive charge of the droplets, is chosen, trace metals are repelled and oxidation is likely to be reduced (Mei et al., 1999).

The droplet size may also affect lipid oxidation. Emulsions with a small oil droplet size will have a large interfacial area. Oxidation, to a large extent, is initiated at the interface between oil and water, where prooxidative metal ions can react with already existing lipid hydroperoxides, whereby they are broken down and foods will be given. Obviously, the different

oxidation is initiated. A large interfacial area will therefore increase the probability of such reactions and in turn, increase the oxidation rate. However, as will be discussed later, other factors than the mere total interfacial area may be more important for lipid oxidation. Another important factor is the processing conditions including temperature and homogenization pressure.

Lipid oxidation may be prevented by the addition of antioxidants. Antioxidants act by different mechanisms. The most important mechanisms are scavenging of free radicals or oxygen or chelation of metal ions. Free radical scavengers may be capable of scavenging free lipid radicals, peroxyl or alkoxyl radicals.

Antioxidant efficacy in multiphase systems depends on many factors, but particularly, the partitioning of the antioxidant into different phases seems to be an important factor because the partitioning will determine their localisation in multiphase systems. The relationship between antioxidant partitioning and antioxidant efficacy is also described as the polar paradox (Porter, 1993; Huang et al., 1996; Frankel et al., 1994). According to the polar paradox, polar antioxidants like ascorbic acid and Trolox are more active in non-polar media like bulk oils than their more non-polar counterparts, ascorbyl palmitate and tocopherol. In contrast, non-polar antioxidants such as tocopherol and ascorbyl palmitate are more active in polar systems like O/W emulsions. These apparent paradoxical effects of the antioxidants have been suggested to be a result of the polar antioxidants being located at the air-oil interface in bulk oils where oxidation is suggested to take place. Likewise, the nonpolar, lipid soluble antioxidants will be located in the oil phase of the emulsion where oxidation propagates. On the other hand, polar

1. Ingredients (amount, type and quality)

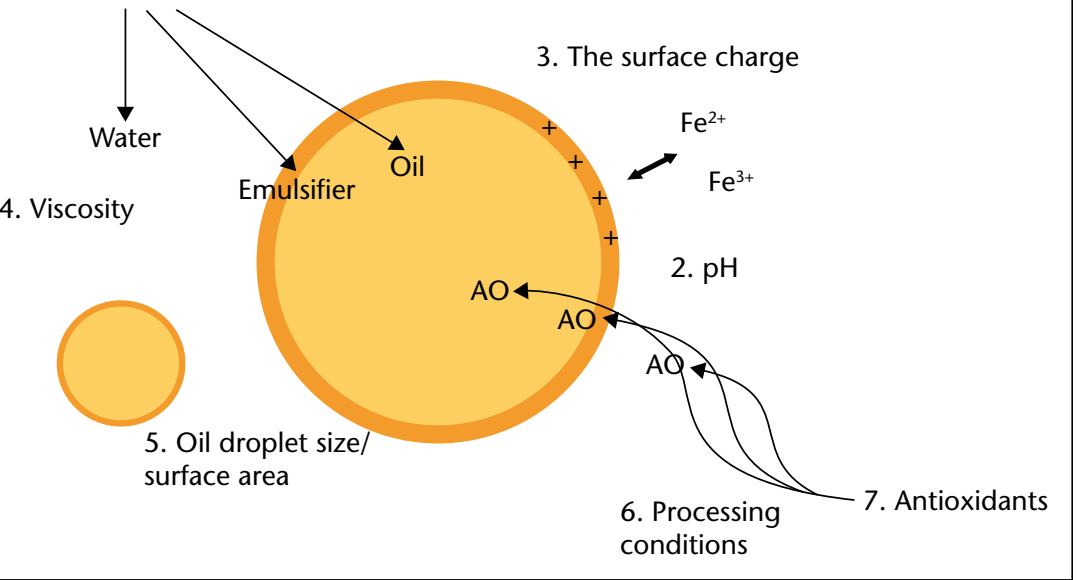

Figure 3. Important factors affecting lipid oxidation in food emulsions. antioxidants will be located in the aqueous phase of the emulsion, where their concentration generally will be too dilute to have any effect. However, other factors than partitioning may in some food systems be more important for the efficacy of antioxidants.

\section{Effect of fish oil quality}

The peroxide value (PV) has traditionally been used as one of the measures of the quality of fish oil. We found that the fish oil quality immediately affected oxidative flavour deterioration in milk enriched with $0.5 \%$ fat (total fat $1.5 \%$ ) (Let et al., 2004; Let et al., 2005). Thus, pasteurised milk emulsions based on cod liver oil with a slightly elevated PV of $1.5 \mathrm{meq} / \mathrm{kg}$ oxidised significantly faster than a similar emulsion containing tuna oil with a low PV of $0.1 \mathrm{meq} / \mathrm{kg}$, despite the fact that the tuna oil was more unsaturated than the cod liver oil (Let et al., 2004). We suggested that the slightly elevated level of lipid hydroperoxides in combination with trace metals present in the milk were responsible for the rapid oxidative flavour deterioration of the cod liver oil enriched milk due to the ability of trace metals to decompose lipid hydroperoxides. A subsequent study supported these findings and also showed that a sensory panel was able to distinguish milk emulsions produced with fish oil with a PV of $0.1 \mathrm{meq} / \mathrm{kg}$ as being less fishy and rancid as compared to milk produced with fish oil having a PV of $0.5 \mathrm{meq} / \mathrm{kg}$ already after 1 day of storage (Let et al., 2005a).

\section{Effect of using a delivery system}

Omega-3 lipids may be added to foods either as neat oils, microencapsulated fish oil or as a pre-emulsified oil. We have investigated the effect of the delivery system in different food models. In fish paté, addition of omega-3 PUFA in the form of microencapsulated fish oil resulted in the most stable product, followed by pre-emulsified fish oil. In contrast, PV in fish paté with neat fish oil increased dramatically during storage at $2{ }^{\circ} \mathrm{C}$ up to 12 weeks (Nielsen and Jacobsen, 2010). All fish patés contained $5 \%$ fish oil.

In another study, oxidative stability of salad dressing, yoghurt and milk enriched with neat fish oil or fish oil-in-water emulsion (50\% oil) prepared with whey protein as an emulsifier was compared (Let et al., 2007a). The salad dressing was prepared with $25 \%$ fat of which $40 \%$ was fish oil. Whey protein was used as emulsifier and a mixture of guar gum, xanthan gum and acetylated distarch adipate were added as stabilisers. Volatiles and sensory data indicated a better oxidative stability of dressing with neat fish oil compared to the dressing with the fish oil-in-water emulsion (figure 4). Hence, 


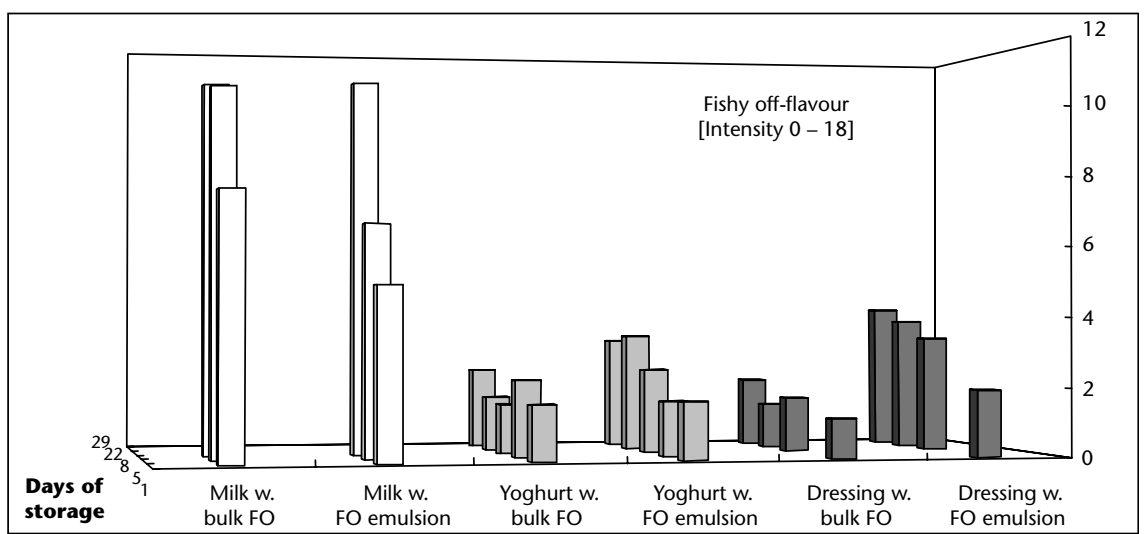

Figure 4. Summarized intensity of fishy odour and flavour of milk, yoghurt and dressing enriched with either neat fish oil or fish oil-in-water emulsion. Average standard deviations were 1.9, 1.3 and 1.4 for milk, yoghurt and dressing, respectively. Reprinted from Let MB, Jacobsen C, Meyer AS (2007). Lipid oxidation in milk, yoghurt and salad dressing enriched with neat fish oil or pre-emulsified fish oil. I Agric Food Chem 55: 7802-9 with permission from ACS Publications.

in this food system, pre-emulsification of the fish oil did not lead to increased oxidative stability. We suggested that this finding could be due to increased oxidation in the fish oilin-water emulsion itself, which was caused by the initial temperature increase $\left(65^{\circ} \mathrm{C}, 3 \mathrm{~min}\right)$ during homogenization of this emulsion. Likewise, we found that addition of preemulsified fish oil did not reduce lipid oxidation in fish oil enriched yoghurt compared to addition of neat fish oil. In contrast to these findings, the addition of fish oil as an oil-in-water emulsion reduced lipid oxidation in milk as compared to addition of omega-3 PUFA in the form of neat fish oil (figure 4).

\section{Effect of ingredients}

The above mentioned comparison of the oxidative stability of fish oil enriched milk and yoghurt clearly showed that fish oil enriched yoghurt had a much better oxidative stability than fish oil enriched milk (Let et al., 2007a). Likewise, another study showed that a strawberry flavoured yoghurt drink had a very high oxidative stability (Nielsen et al., 2007). It was therefore investigated if the ingredients added to the strawberry flavoured yoghurt drink had an effect on oxidation. As shown in table 1, it was not possible to conclude on possible antioxidative effects of the added ingredients due to a high stability, even of plain yoghurt with fish oil added (Nielsen et al., 2009). In addition, this study confirmed that fish oil enriched milk was more susceptible to oxidation than yoghurt. We hypothesized that the high oxidative stability of fish oil enriched yoghurt could be due to antioxidative activity of peptides formed during the fermentation of milk. To investigate this hypothesis, peptides formed during fermentation of yoghurt were isolated and fractionated (Farvin et al., 2010a). Subsequently, the antioxidant activity of the peptides were analysed by different in vitro assays, including the DPPH radical scavenging activity, $\mathrm{Fe}^{2+}$ chelating activity, reducing power and inhibition of oxidation in liposome model system. Overall, the assays showed that the peptides of lower molecular weight had good metal chelating and iron reducing properties, whereas the higher molecular weight peptides were more efficient radical scavengers and exerted a better effect in the liposome model (Farvin et al., 2010a). Further, the low molecular weight peptides were evaluated in fish oil enriched milk and they were shown to exert almost the same antioxidative effect as caseinophosphopetides (figure 5). It was also observed that the yoghurt contained a considerable amount of free amino acids, such as His, Tyr, Thr and Lys, which have been reported to have antioxidant properties (Farvin et al., 2010b). The identified peptides comprised a few $\mathrm{N}$-terminal fragments of $\alpha s_{1}$-casein, $\alpha \mathrm{s}_{2}$-casein, $\mathrm{k}$-casein and several fragments from $\beta$-casein. Almost all the peptides identified contained at least one proline residue. Some of the identified peptides included the hydrophobic amino acid residues Val or Leu at the $\mathrm{N}$-terminus of the peptides and Pro, His or Tyr in the sequence which is the characteristic of antioxidant peptides (Farvin et al., 2010b).

We also speculated whether the bacteria used for fermenting yoghurt would lower the oxygen content and thereby decrease oxidation. Therefore, the oxygen content of the yoghurt was measured and it was found to be lower than that of milk (Farvin et al., 2010a). Hence, the higher oxidative stability of yoghurt might be due to the presence of antioxidant peptides and free amino acids formed during fermentation of the yoghurt. Furthermore, the lower
Table 1. Sensory evaluation of fishy flavour in milk and yoghurt emulsions enriched with fish oil during storage at $2^{\circ} \mathrm{C}$. Numbers are given as avg \pm stdev. $N=9$.

\begin{tabular}{|llll|}
\hline & Week 0 & Week 1 & Week 3 \\
\hline$M$ & $5.4 \pm 1.5^{\mathrm{b}}$ & $6.0 \pm 2.4^{\mathrm{b}}$ & $7.4 \pm 1.0^{\mathrm{b}}$ \\
\hline$Y$ & $0.5 \pm 0.4^{\mathrm{a}}$ & $0.8 \pm 1.0^{\mathrm{a}}$ & $1.6 \pm 1.2^{\mathrm{a}}$ \\
\hline$Y+C A$ & $0.4 \pm 0.5^{\mathrm{a}}$ & $0.7 \pm 1.0^{\mathrm{a}}$ & $1.3 \pm 0.9^{\mathrm{a}}$ \\
\hline$Y+G D L$ & $0.9 \pm 1.4^{\mathrm{a}}$ & $1.2 \pm 1.5^{\mathrm{a}}$ & $1.7 \pm 1.7^{\mathrm{a}}$ \\
\hline$Y+C A+P$ & $0.4 \pm 0.5^{\mathrm{a}}$ & $0.9 \pm 1.4^{\mathrm{a}}$ & $1.0 \pm 1.3^{\mathrm{a}}$ \\
\hline$Y+G D L+P$ & $0.9 \pm 1.1^{\mathrm{a}}$ & $1.2 \pm 1.7^{\mathrm{a}}$ & $1.5 \pm 1.3^{\mathrm{a}}$ \\
\hline$Y+C A+P+F S$ & $0.0 \pm 0.1^{\mathrm{a}}$ & $0.5 \pm 1.0^{\mathrm{a}}$ & $0.4 \pm 0.7^{\mathrm{a}}$ \\
\hline$Y+G D L+P+F S$ & $0.2 \pm 0.5^{\mathrm{a}}$ & $0.2 \pm 0.4^{\mathrm{a}}$ & $0.4 \pm 0.5^{\mathrm{a}}$ \\
\hline
\end{tabular}

M: milk, Y: yoghurt, CA: citric acid, GDL: gluconodelta-lactone, P: pectin ( $2 \%$ solution), FS: fruit preparation and sugar. Values with different letters within a column are significantly different $(P<0.001)$. Reprinted from Nielsen NS, Klein A, Jacobsen C. Effect of ingredients on oxidative stability of fish oil enriched drinking yoghurt. Eur / Lipid Sci Technol 2009;111: 337-45 with permission from Wiley.

oxygen content of yoghurt may also have contributed to the enhanced oxidative stability of fish oil enriched yoghurt compared to fish oil enriched milk.

We have also investigated the effect of the ingredients in a completely different food system, namely mayonnaise-based shrimp salad. Interestingly, a sensory panel could not significantly distinguish the intensity of rancid offflavour in salads without fish oil from that in salads with fish oil throughout the storage period (57 days) (Sørensen et al., 2010). These results thus indicated that it was possible to add fish oil to shrimp salad without compromising the sensory properties if the labelled shelf life was kept below 57 days. Further, it was found that addition of shrimp had a prooxidative effect, whereas asparagus had an antioxidative effect, which was efficient enough to prevent the prooxidative effect of the shrimps in this type of salad.

\section{Effect of emulsification conditions}

To investigate the effect of emulsification conditions for incorporation of $0.5 \%$ fish oil into milk (total fat content 1.5\%), different temperatures $\left(50\right.$ and $72{ }^{\circ} \mathrm{C}$ ) and pressures $(5,15$ and $22.5 \mathrm{MPa}$ ) were evaluated (Let et al., 2007b; Sørensen et al., 2007). It was observed that high temperature and high pressure $\left(72{ }^{\circ} \mathrm{C}-22.5 \mathrm{MPa}\right)$ resulted in less lipid oxidation, whereas low pressure and low temperature $\left(50{ }^{\circ} \mathrm{C}-5 \mathrm{MPa}\right)$ resulted in faster 


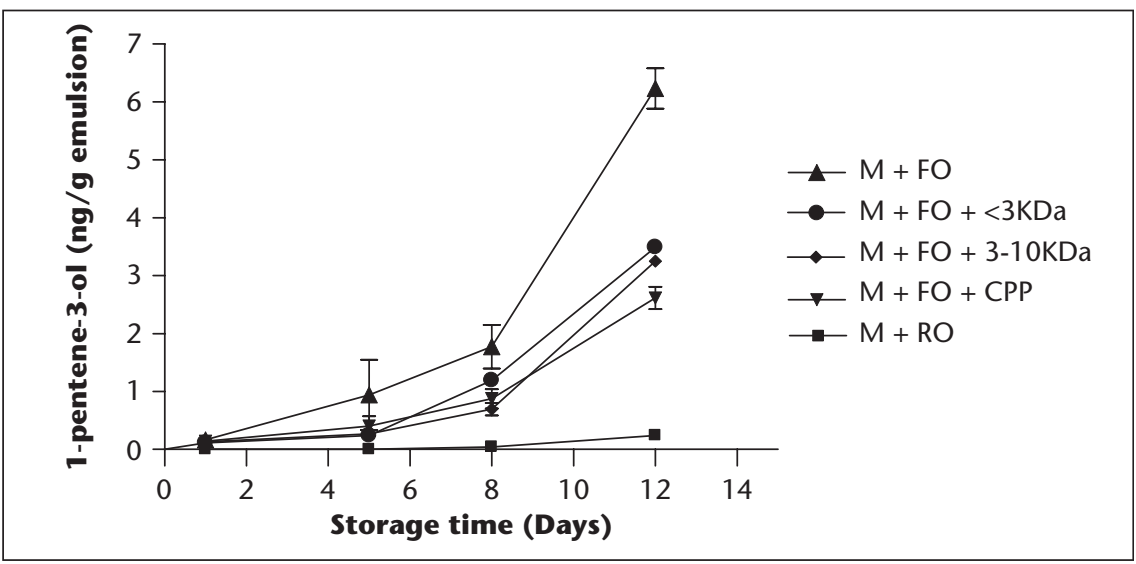

Figure 5. Effect of yoghurt peptides on formation of 1-penten-3-ol in fish oil enriched milk during storage at $2^{\circ} \mathrm{C}$. M: Milk, FO: Milk with $0.5 \%$ fish oil, RO: Milk with $0.5 \%$ rapeseed oil, < $3 \mathrm{kDa}$ : peptides smaller than $3 \mathrm{kDa}$, 3-10 kDa: peptides from the 3-10 kDa fraction, CPP: caseinophosphopeptides. Reprinted from Farvin KHS, Baron CP, Nielsen NS, Jacobsen C (2010). Antioxidant activity of yoghurt peptides: Part 1 - in vitro assays and evaluation in $\bigotimes-3$ enriched milk. Food Chem 123: $1081-9$ with permission from Elsevier.

lipid oxidation. It is well known that lipid oxidation rates increase with increasing temperatures. Moreover, homogenization at high temperature and pressure resulted in the smallest droplet size, i.e. the largest total interfacial area, which in theory could also promote oxidation. The results were therefore somewhat surprising. As already mentioned, lipid oxidation has been suggested to be initiated at the oil-water interface. We hypothesized that the different homogenization conditions had affected the protein composition at the oil-water interface and that this could explain the surprising findings. To investigate this hypothesis, SDS-PAGE and confocal laser scanning microscopy were

used to study the effect of the homogenization conditions on the composition of the oil-water interface and the location of selected proteins in the milk, respectively. The results suggested that a high temperature resulted in an increase in $\beta$-lactoglobulin adsorbed at the oil-water interface, and this was even more pronounced with higher pressure (Sørensen et al., 2007). In contrast, less casein seemed to be present at the oil-water interface with increasing pressure. We therefore suggested that a combination of more $\beta$-lactoglobulin and less casein at the oil-water interface was responsible for the increased oxidative stability at high temperature and pressure. Hence, these results demon-

Table 2. Summarized main findings on antioxidant effects in different omega-3 PUFA enriched foods.

\begin{tabular}{|llllllll|}
\hline & Tocopherol & $\begin{array}{l}\text { Ascorbyl } \\
\text { palmitate }\end{array}$ & $\begin{array}{l}\text { Ascorbic } \\
\text { acid }\end{array}$ & & $\begin{array}{l}\text { EDTA } \\
\text { Propyl } \\
\text { gallate/ } \\
\text { Gallic } \\
\text { acid }\end{array}$ & $\begin{array}{l}\text { Lacto- } \\
\text { ferrin }\end{array}$ & $\begin{array}{l}\text { Caffeic } \\
\text { acid }\end{array}$ \\
\hline $\begin{array}{l}\text { Milk } \\
1.5 \% \text { fat }\end{array}$ & Weak anti & Anti & - & $\begin{array}{l}\text { Anti } \\
\text { to no }\end{array}$ & - & - & - \\
\hline $\begin{array}{l}\text { Milk drink } \\
5 \% \text { fat }\end{array}$ & - & Pro & - & Anti & - & Weak & - \\
anti to & \\
pro & & \\
$1.5 \%$ fat & - & - & - & Anti & - & - & - \\
\hline $\begin{array}{l}\text { Dressing } \\
25 \% \text { fat }\end{array}$ & Weak anti & Pro & - & Anti & - & - & - \\
\hline $\begin{array}{l}\text { Mayonnaise } \\
80 \% \text { fat }\end{array}$ & $\begin{array}{l}\text { Weak anti } \\
\text { to pro }\end{array}$ & Pro & Pro & Anti & Pro & $\begin{array}{l}\text { Weak } \\
\text { anti to }\end{array}$ & - \\
pro & \\
\hline $\begin{array}{l}\text { Energy bars } \\
6.2 \% \text { fat }\end{array}$ & $\begin{array}{l}\text { Anti to } \\
\text { weak pro }\end{array}$ & Pro & - & Pro & - & - & Pro \\
\hline
\end{tabular}

strated that the composition of the interface is very important and that thermal oxidation may not necessarily trigger lipid oxidation. Rather, in the case of milk emulsions, this high temperature can result in unfolding of the proteins at the interface, which in turn gives the highest protection against oxidation.

\section{The effect of antioxidant addition}

As already mentioned, the efficacy of antioxidants can be affected by different factors, such as their partitioning properties, but also interaction with other ingredients including emulsifiers and trace metals may affect their efficacy. We have investigated the effect of a range of different antioxidants in different fish oil enriched foods. Table 2 shows a simplified summary of the main findings. For further details, refer to the original manuscripts cited in the following or to a recent review by Jacobsen et al. (2008a), which includes a quantitative comparison of the effect of antioxidants in fish oil enriched milk, milk drink, mayonnaise and dressing, or to Jacobsen et al. (2008b), which also includes data of fish oil enriched foods such as energy bars.

\section{Effect of tocopherols}

We have evaluated the effect of tocopherols in fish oil enriched mayonnaise, salad dressing, milk, milk drink and energy bar (table 2). It should be stressed that the difference between fish oil enriched milk and milk drink was that milk contained $1.5 \%$ fat in total and no added emulsifier or flavours, whereas the milk drink contained $5 \%$ total lipids, emulsifiers and stabilisers, as well as strawberry flavour.

Interestingly, tocopherols did not exert significant antioxidative effects in emulsified omega3 PUFA enriched food emulsions, whereas the opposite was the case in energy bars. Thus, a mixture of the tocopherol homologues were found either to promote oxidation in mayonnaise when applied in high concentrations (above $16 \mathrm{mg} / \mathrm{kg}$ product) or to have either no or a weak effect when applied in lower concentrations (Jacobsen et al., 2008a; Jacobsen et al., 2000; Jacobsen et al., 2001a). This was independent of whether the tocopherol mixture was added with oil as a carrier or with a hydrophilic carrier, which enabled solubilisation of the antioxidant mixture in the aqueous phase of the mayonnaise before emulsification. In salad dressing and milk, $\gamma$-tocopherol was found to exert some antioxidative effect depending on its concentration, while $\alpha$-tocopherol was a prooxidant in milk (Jacobsen et al., 2008a; Let et al., 2007; Let et al., 2005b). The effect of $\alpha$-tocopherol was 
not investigated in salad dressing. In milk, the highest antioxidative activity of $\gamma$-tocopherol was observed at a concentration of $1.65 \mathrm{mg} / \mathrm{kg}$ product (Jacobsen et al., 2008a; Let et al., 2005b). In addition, $\gamma$-tocopherol was found to have a good antioxidative effect in energy bars with the best protective effect observed at a concentration of $33 \mathrm{mg} / \mathrm{kg}$ product. Interestingly, tocopherol was a prooxidant when added in low concentrations (Horn et al., 2009).

We proposed that the lacking antioxidative effect of the tocopherols in mayonnaise and salad dressing was due to the finding that in these food systems, oxidation is mainly due to metal catalyzed breakdown of peroxides from omega-3 PUFA located in the aqueous phase or at the o/w interface (Jacobsen et al., 2008a). Therefore, tocopherol can only to a limited extent reduce oxidation by inhibiting oxidative deterioration of omega-3 PUFA inside the oil droplet. The finding that tocopherol is an efficient antioxidant in energy bars suggests that the free radical scavengers can reduce lipid oxidation in this food system, which means that initiation of lipid oxidation by already existing free radicals may be an important factor (Jacobsen et al., 2008b; Horn et al., 2009).

\section{Effect of ascorbic acid and ascorbyl palmitate}

Ascorbic acid was evaluated in mayonnaise and ascorbyl palmitate in mayonnaise, salad dressing, milk, milk drink and energy bar (table 2). Ascorbic acid and ascorbyl palmitate exerted strong prooxidative activity in mayonnaise (Jacobsen et al., 2008a; Jacobsen et al., 1999; Jacobsen et al., 2001b) and energy bars (Horn et al., 2009). In contrast, both weak prooxidative and antioxidative effects were found in salad dressing (Let et al., 2007) and in milk drink (Jacobsen et al., 2008a) depending on the concentration applied. For energy bars, the strong prooxidative effect was only observed at high concentrations of ascorbyl palmitate $(15 \mathrm{mg} / \mathrm{kg}$ product), whereas weaker prooxidative effects were observed at the lowest concentration $(3.75 \mathrm{mg} / \mathrm{kg}$ product) (Horn et al., 2009). Similarly, for milk drink, the strongest prooxidative effect was observed when ascorbyl palmitate was added in highest concentration (15 mg/kg product), whereas only weak prooxidative effects were found when the concentration was lowest (3.75 mg/kg product). Interestingly, ascorbyl palmitate did prevent the formation of certain volatiles such as hexanal in milk drink, but it promoted the formation of other volatiles such as nonadienal and it also promoted the formation of fishy off-flavour (Jacobsen et al., 2008a). In contrast, ascorbyl palmitate effi- ciently inhibited oxidative flavour deterioration in milk when added in a concentration of $1.5 \mathrm{mg} / \mathrm{kg}$ (Let et al., 2005b). The prooxidative effects of ascorbic acid and ascorbyl palmitate in mayonnaise, salad dressing and energy bar were suggested to be due to their ability to reduce $\mathrm{Fe}^{3+}$ to $\mathrm{Fe}^{2+}$, and in the case of mayonnaise to release protein-bound iron in the egg yolk located at the oil-water interface into the aqueous phase, where iron is more prooxidative (Jacobsen et al., 2008a). The antioxidative effect of ascorbyl palmitate was suggested to be due to its ability to regenerate tocopherol (Jacobsen et al., 2008a). The different effects observed in milk drink and milk was explained by the different compositions of the two milk systems (Jacobsen et al., 2008a). As mentioned before, fish oil enriched milk did not contain any additives, and the milk drink contained emulsifiers and stabilizers, which may have reduced the ability of ascorbyl palmitate to regenerate tocopherol. Another possible explanation for the different effects of ascorbyl palmitate in the two systems could be the different antioxidant concentrations applied in milk and milk drink. It cannot be ruled out that ascorbyl palmitate could also have an antioxidative effect in milk drink at lower concentrations and this might also be the case in energy bars.

\section{Effect of EDTA}

The metal chelator EDTA was evaluated in mayonnaise, dressing, milk and milk drink (Let et al., 2004; Jacobsen et al., 2008a; Let et al., 2007c; Let et al., 2005b; Jacobsen et al., 2001; TimmHeinrich et al., 2004). The results showed that EDTA efficiently prevented oxidation in mayonnaise, salad dressing and milk drink, where it exerted upto $94 \%$ reduction in fishy flavour formation in both mayonnaise and milk drink. Moreover, it was found that the antioxidative efficacy of EDTA in salad dressing could be further improved by the simultaneous addition of $\gamma$-tocopherol and ascorbyl palmitate (Let et al., 2007). Similar effects may be foreseen in mayonnaise. EDTA did not have a clear antioxidative effect in fish oil enriched milk (Let et al., 2004; Jacobsen et al., 2008a; Let et al., $2005 b)$. Thus, when a low fish oil concentration $(0.5 \%)$ or when a very high quality fish oil (PV $<0.2 \mathrm{meq} / \mathrm{kg}$ ) was used for supplementation with a high fish oil concentration (1.5\%), EDTA only slightly reduced oxidation. In contrast, EDTA seemed to be more efficient when a high concentration of fish oil of a less good quality (PV $1.5 \mathrm{meq} / \mathrm{kg}$ ) was used (Let et al., 2004). The reason for the better effects of EDTA in milk emulsions containing fish oil of a lower quality was most likely that oxidation was much more pronounced in this emulsion and therefore, the effect of EDTA was easier to detect. In another study on a milk drink containing $5 \%$ fat of which $0.5 \%$ (absolute value) was enzyme modified fish oil, EDTA effectively reduced off-flavour formation (Timm-Heinrich et al., 2004).

In energy bars, EDTA had considerably prooxidative effects regardless of the concentration added (5-100 mg/kg product). We hypothesized that the EDTA to iron ratio was too low to obtain an antioxidative effect in this system (Jacobsen et al., 2008b; Horn et al., 2009).

\section{Effect of lactoferrin}

We have only evaluated the effect of lactoferrin in fish oil enriched mayonnaise and milk drink. In both systems, it appeared to exhibit a concentration dependent effect, but even at its optimum level, it only exerted a weak antioxidative effect (Timm-Heinrich et al., 2004; Nielsen et al., 2004). The poor antioxidative effect of lactoferrin may be due to its relatively low binding constant towards $\mathrm{Fe}^{3+}$, which may imply that it is not able to bind iron in an efficient manner (Jacobsen et al., 2008a). It is also possible that lactoferrin loses its metal chelating properties at low $\mathrm{pH}$ values as that of mayonnaise $(\mathrm{pH} 4)$ or during heating processes as that used to prepare the milk drink (Jacobsen et al., 2008a; Nielsen et al., 2004).

\section{Effect of gallic acid, propyl gallate and caffeic acid}

We evaluated gallic acid and propyl gallate in mayonnaise and gallic acid in milk drink. In addition, caffeic acid was evaluated in energy bars (Nielsen et al., 2004; Jacobsen et al., 1999; Timm-Heinrich et al., 2003). Propyl gallate and gallic acid promoted oxidation in mayonnaise when added in concentrations of $40 \mathrm{mg} / \mathrm{kg}$ product and $200 \mathrm{mg} / \mathrm{kg}$ product, respectively. Gallic acid did not have any clear antioxidative effect in milk drink. Caffeic acid strongly promoted oxidative flavour deterioration in energy bars when added in concentrations from $3.75 \mathrm{mg} / \mathrm{kg}$ to $15 \mathrm{mg} / \mathrm{kg}$ product (Horn et al., 2009). The prooxidative effects of these antioxidants were ascribed to their ability to reduce $\mathrm{Fe}^{3+}$ to $\mathrm{Fe}^{2+}$ (Horn et al., 2009; Nielsen et al., 2004; Jacobsen et al., 1999; Timm-Heinrich et al., 2003).

\section{Effect of spices}

In addition to the commercially available antioxidants listed in table 2, we have also evaluated the effect of spices in fish oil enriched tuna salad and the effect of lipophilized antioxidants in milk and model emulsions.

We added $1 \%$ oregano, rosemary or thyme to fish oil enriched tuna salad to evaluate their effect on lipid oxidation (Sørensen et al., 2010). 
The results showed that the addition of spices increased the oxidative stability of tuna salad and that oregano was the most efficient antioxidant followed by rosemary and thyme. However, when added in this concentration (1\%), the flavour of the spices was relatively strong, meaning that the tuna salad had a entirely different flavour from the traditional product. Experiments with oregano extracts did not show a clear effect of the extract (unpublished data).

\section{Effect of lipophilized compounds}

Phenolic compounds such as polyphenols and phenolic acids generally have good antioxidative properties. Phenolic acids and several other phenolic compounds are polar compounds that to a high degree will be localized in the aqueous phase of emulsions, where they cannot exert their antioxidative activity. It has therefore been suggested that lipophilization of the compounds by esterification with fatty acids could improve their efficacy. We have recently evaluated the applicability of this strategy in fish oil enriched emulsion (simple model system) and milk (Sørensen, 2010). Two different phenolic compounds were esterified (dihydrocaffeic acid and rutin) with different fatty acids (C8 or $\mathrm{C} 18$ and $\mathrm{C} 12$ and $\mathrm{C} 16$, respectively). In the o/w emulsion, octyl dihydrocaffeate and oleyl dihydrocaffeate were stronger antioxidants than dihydrocaffeic acid, which acted as a prooxidant. Moreover, octyl dihydrocaffeate was more efficient than oleyl dihydrocaffeate and this finding supported a recently reported cut-off effect, which suggested that lipophilization will only increase antioxidant efficacy in emulsions up to a chain length of 12 carbon atoms in the acyl chain (Laguerre et al., 2009). The cut-off effect was suggested to be due to the formation of micelles when the acyl chain is longer than 12 carbon atoms. In fish oil enriched milk, octyl dihydrocaffeate was also more efficient as antioxidant compared to oleyl dihydrocaffeate; however, the differences in their antioxidant efficacy was not as large as observed in the o/w emulsions (Sørensen, 2010). Furthermore, rutin esters were stronger antioxidants than rutin in fish oil enriched milk, and the same effect of the chain length as observed for dihydrocaffeic acid esters was also observed here. On the basis of these results, it was concluded that the cut-off effect was not only specific for the individual lipophilized phenolic compounds, but also depending on the emulsion system, e.g. simple emulsions and complex food emulsions. However, to be able to further conclude on the optimal acyl chain esterified to dihydrocaffeate and rutin in relation to their strongest antioxidant protection, further research is needed with several different acyl chain lengths and in a range of different emulsion systems (Sørensen, 2010).

\section{Conclusion}

As demonstrated in this review, lipid oxidation gives rise to great challenges when enriching foods with omega-3 PUFA. It is also clear that the challenges are greater for some products than for others. For example, fish oil enriched milk is much more susceptible to lipid oxidation than yoghurt. These differences are due to the fact that several different factors can affect lipid oxidation rate in complex food matrices. It was demonstrated that in oxidation sensitive systems such as milk, the oil quality is extremely important. For this product, the fish oil must be of superior quality in order to obtain a product with acceptable sensory properties and shelf life.

Omega-3 lipids can be added to foods in the form of neat oils, microencapsulated fish oil or as an fish oil-in-water emulsion. In some food systems, neat oils may result in the best final quality, whereas in other food systems, the microencapsulated or emulsified fish oil may work better. It should be stressed that the same emulsified fish oil may work well in one food system, but may result in a less oxidatively stable product than when neat oil is used when added in another food product as illustrated by the milk, dressing and yoghurt examples in this presentation. Hence, the delivery system for omega-3 PUFA should be carefully considered. It was also illustrated that the composition of the oil-water interface significantly will affect the oxidative stability of the fish oil enriched product and that it, at least for some products such as milk, is possible to change this composition by changing the emulsification conditions. Hence, it is very important to optimise the emulsification process for each specific food product.

As demonstrated by the milk versus yoghurt case, as well as the shrimp salad case, the composition of the food matrix can significantly affect lipid oxidation. In the case of yoghurt, the peptides formed during milk fermentation appear to be efficient antioxidants. This property of the milk peptides may perhaps be exploited in other omega- 3 enriched foods. Several factors can affect the efficacy of antioxidants. Therefore, the same antioxidant can have very different effects in different food systems. Lipophilization of antioxidants to improve their efficacy has shown promising results. However, this strategy is not straightforward, as it is not yet possible to predict the required chain length of the acyl group to obtain an optimal efficacy. These findings also suggest that the polar paradox may be too simple for predicting antioxidant efficacies. Therefore, a better quantitative understanding of the different effects of antioxidants in different food systems is required and more research is needed.

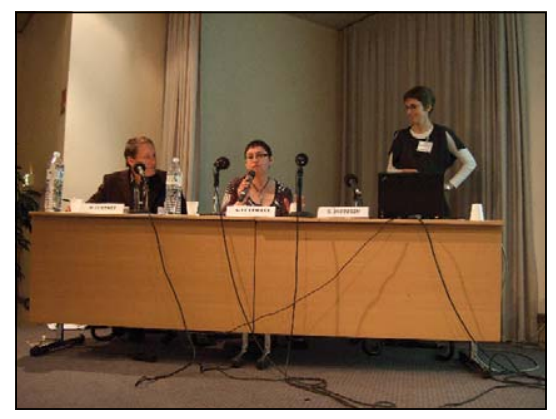

Acknowledgements. I am sincerely grateful to Association Francaise pour l'Etude des Corps Gras (AFECG) for awarding me the Chevreul Medal 2010 (photo). I would also like to thank all my co-workers who throughout the years have contributed to the results, which resulted in the medal. I would particularly like to thank the following colleagues: Caroline Baron, Maike Timm-Heinrich, Nina Skall Nielsen, Sabeena Farvin, Mette Bruni Let, Anna F. Horn, Ann-Dorit Moltke Sørensen, Lis Berner, Inge Holmberg, Trang Vu, Jane Jørgensen, Bena Marie Lue, Xuebing Xu, Gudipati Venkateshwarlu, Karsten Hartvigsen, Pia Lund, Anne Meyer, Torger Børresen and Jens Adler-Nissen (all current or former colleagues from the Technical University of Denmark).

\section{REFERENCES}

Dyerberg J, Bang HO. Hemostatic function and platelet poly-unsaturated fatty-acids in eskimos. Lancet 1979; 2: 433-5.

Farvin KHS, Baron CP, Nielsen NS, Jacobsen C. Antioxidant activity of yoghurt peptides: part 1- in vitro assays and evaluation in $\mathbb{\bigotimes}-3$ enriched milk. Food Chem 2010a; 123: 1081-9.

Farvin KHS, Baron CP, Nielsen NS, Otte J, Jacobsen C. Antioxidant activity of yoghurt peptides: part 2 characterisation of peptide fractions. Food Chem 2010b; 123: 1090-7.

Frankel EN, Huang S-W, Kanner J, German JB. Interfacial phenomena in the evaluation of antioxidants: bulk oils vs emulsions. I Agric Food Chem 1994; 42: 1054-9.

Frankel EN. Lipid Oxidation. Dundee: The Oily Press, 2005.

Horn AF, Nielsen NS, Jacobsen C. Addition of caffeic acid, ascorbyl palmitate or $\gamma$-tocopherol to fish oil enriched energy bars affects lipid oxidation differently. Food Chem 2009; 112: 412-20. 
Huang SW, Hopia A, Schwarz K, Frankel EN, German JB. Antioxidant activity of $\alpha$-tocopherol and trolox in different lipid substrates: bulk oils vs oil-in-water emulsions. J Agric Food Chem 1996; 44: 444-52.

Jacobsen C, Adler-Nissen J, Meyer AS. The effect of ascorbic acid on iron release from the emulsifier interface and on the oxidative flavor deterioration in fish oil enriched mayonnaise. / Agric Food Chem 1999; 47: 4917-26.

Jacobsen C, Hartvigsen K, Lund P, et al. Oxidation in fish oil enriched mayonnaise: 1. Assessment of propyl gallate as antioxidant by discriminant partial least squares regression analysis. $Z$ Lebensm Unters Forsch 1999; 210: 13-30.

Jacobsen C, Hartvigsen K, Lund P, Adler-Nissen I, Hølmer G, Meyer AS. Oxidation in fish oil enriched mayonnaise: 2. Assessment of the efficacy of different tocopherol antioxidant systems by discriminant partial least squares regression analysis. Eur Food Res Technol 2000; 210: 242-57.

Jacobsen C, Hartvigsen K, Lund P, et al. Oxidation in fish oil enriched mayonnaise: 4 . Effect of tocopherol concentration on oxidative deterioration. Eur Food Res Technol 2001a; 212: 308-18.

Jacobsen C, Timm M, Meyer AS. Oxidation in fish oil enriched mayonnaise: ascorbic acid and low $\mathrm{pH}$ increase oxidative deterioration. I Agric Food Chem 2001b; 49: 3947-56.

Jacobsen C, Hartvigsen K, Thomsen MK, et al. Lipid oxidation in fish oil enriched mayonnaise: calcium disodiumethylenediaminetetraacetate, but not gallic acid, strongly inhibited oxidative deterioration. J Agric Food Chem 2001c; 49: 1009-19.

Jacobsen C, Let MB, Nielsen NS, Meyer AS. Antioxidant strategies for preventing oxidative flavour deterioration of foods enriched with $n-3$ polyunsaturated lipids: a comparative evaluation. Trends Food Sci Technol 2008a;19: 76-93.

Jacobsen C, Let MB, Sørensen ADM, Horn AF, TimmHeinrich M, Nielsen NS. Applications of natural antioxidants in omega-3 enriched foods. Electron J Environ Agric Food Chem 2008b; 7: 3288-95.
Laguerre M, Giraldo LJL, Lecomte J, et al. Chain length affects antioxidant properties of chlorogenate esters in emulsion: the cutoff theory behind the polar paradox. J Agric Food Chem 2009; 57: 11335-42.

Let MB, Jacobsen C, Meyer AS. Effects of fish oil type, lipid antioxidants and presence of rapeseed oil on oxidative flavour deterioration of fish oil enriched milk. Eur J Lipid Sci Technol 2004; 106: 170-82.

Let MB, Jacobsen C, Meyer AS. Sensory stability and oxidation of fish oil enriched milk is affected by milk storage temperatures and oil quality. Internat Dairy I 2005a; 15: 173-82.

Let MB, Jacobsen C, Pham KA, Meyer AS. Protection against oxidation of fish oil enriched milk emulsions through addition of rapeseed oil or antioxidants. J Agric Food Chem 2005b; 53: 5429-37.

Let MB, Jacobsen C, Meyer AS. Lipid oxidation in milk, yoghurt and salad dressing enriched with neat fish oil or pre-emulsified fish oil. J Agric Food Chem 2007a; 55: 7802-9.

Let MB, Jacobsen C, Sørensen ADM, Meyer AS. Homogenization conditions affects the oxidative stability of fish oil enriched milk emulsions: lipid oxidation. J Agric Food Chem 2007b; 55: 1773-80.

Let MB, Jacobsen C, Meyer AS. Ascorbyl palmitate, gamma-tocopherol, and EDTA affect lipid oxidation in fish oil enriched salad dressing differently. J Agric Food Chem 2007c; 55: 2369-75.

Mei LY, Mcclements DJ, Decker EA. Lipid oxidation in emulsions as affected by charge status of antioxidants and emulsion droplets. I Agric Food Chem 1999; 47: 2267-73.

Nielsen NS, Jacobsen C. Oxidation in fish oil enriched fish paté. Eur Food ResTech 2010 (submitted).

Nielsen NS, Petersen A, Meyer AS, Timm-Heinrich M, Jacobsen $C$. The effects of lactoferrin, phytic acid and EDTA on oxidation in two food emulsions enriched with long chain polyunsaturated fatty acids. J Agric Food Chem 2004; 52: 7690-9.

Nielsen NS, Debnath D, Jacobsen C. Oxidative stability of fish oil enriched drinking yoghurt. Internat Dairy / 2007; 17: 1478-85.
Nielsen NS, Klein A, Jacobsen C. Effect of ingredients on oxidative stability of fish oil enriched drinking yoghurt. Eur / Lipid Sci Technol 2009; 111: 337-45.

Porter WL. Paradoxical behavior of antioxidants in food and biological systems. Toxicol Ind Health 1993; 9: 93-122.

Ruxton CHS, Reed SC, Simpson MJA, Millington KJ. The health benefits of omega-3 poluunsaturated fatty acids: a review of the evidence. J Human Nutrition Diet 2007; 20: 275-85.

Sørensen ADM, Baron $C P$, Let $M B$, Brüggemann $D$, Pedersen LRL, Jacobsen C. Homogenization conditions affects the oxidative stability of fish oil enriched milk emulsions: oxidation linked to changes in the protein composition at the oil-water interface. J Agric Food Chem 2007; 55: 1781-9.

Sørensen ADM, Nielsen NS, Jacobsen C. Oxidative stability of fish oil enriched mayonnaise based salads. Eur J Lipid Sci Technol 2010; 112: 476-87.

Sørensen ADM. The influence of ingredients or lipophilized antioxidants on the oxidative stability of fish oil enriched food systems. Ph.d. thesis. National Food Institute. Technical University of Denmark, 2010.

Timm-Heinrich M, Xu X, Nielsen NS, Jacobsen C. Oxidative stability of milk drink containing structured lipids produced from sunflower oil and caprylic acid. Eur J Lipid Sci Technol 2003; 105: 459-70.

Timm-Heinrich M, Xu X, Nielsen NS, Jacobsen C. Oxidative stability of mayonnaise and milk drink produced with structured lipids based on fish oil and caprylic acid. Eur Food Res Technol 2004; 219: 32-41.

Venkateshwarlu G, Let MB, Meyer AS, Jacobsen C. Chemical and olfactometric characterization of volatile flavor compounds in a fish oil enriched milk emulsion. J Agric Food Chem 2004a; 52: 311-7.

Venkateshwarlu G, Let MB, Meyer AS, Jacobsen C. Modelling the sensory impact of defined combinations of volatile lipid oxidation products on fishy and metallic off-flavors. J Agric Food Chem 2004b; 52: 1635-41. 